\title{
THE NEW ZEALAND COMMITTEE ON PESTICIDE RESISTANCE (NZCPR)
}

\author{
R.M. BERESFORD ${ }^{1}$, G.B. FOLLAS ${ }^{2}$, G.C. HAGERTY ${ }^{3}$, K.C. \\ HARRINGTON $^{4}$ and N.A. MARTIN ${ }^{1}$
}

\author{
${ }^{I}$ The New Zealand Institute for Plant \& Food Research Limited, Mt Albert \\ Research Centre, Private Bag 92169, Auckland, New Zealand \\ ${ }^{2}$ Syngenta Crop Protection Ltd., Tower 2, Level 7, 110 Symonds St, Auckland, \\ New Zealand \\ ${ }^{3}$ BASF New Zealand Ltd, 1/333 Harewood Road, Christchurch, New Zealand \\ ${ }^{4}$ Institute of Natural Resources, Massey University, Palmerston North, \\ New Zealand
}

Corresponding author: RBeresford@hortresearch.co.nz

\section{INTRODUCTION}

New Zealand's primary production relies on pesticides to protect crops against diseases, invertebrate pests and weeds so that our agricultural systems continue to be competitive in world markets. Unfortunately, the repeated use of some pesticides can lead to the development of resistance in some pest species. Pests here include fungi and bacteria (plant diseases), insects and mites (invertebrate pests) and weeds. Resistance is the loss of field control of a pest when a pesticide that would normally give control at recommended application rates is used. It is not a change in the pesticide active ingredient, but rather is a genetic change in the pest that allows individuals in the population to survive in the presence of the pesticide. Resistant individuals are selected by repeated use of the pesticide until they become dominant, possibly leading to pest control failure. Modern selective pesticides, which target specific single sites in pest biochemical pathways, are more likely to select for resistance than older multi-site, broad spectrum pesticides. Consequently, the resistance risk that accompanies new pesticide chemistry is usually well researched and specific resistance management recommendations are generally released along with new pesticides. The main strategies for combating resistance to atrisk pesticides are to limit the number of applications, restrict use to certain crop growth stages and to alternate or mix them with other effective pesticides with a different mode of action.

\section{NZCPR}

The main advocacy group for pesticide resistance management is the New Zealand Committee on Pesticide Resistance (NZCPR), which was first formed in 1989 (Elliott et al. 1989), in conjunction with the New Zealand Plant Protection Society (NZPPS). NZCPR has three Task Groups, one for each of fungicides and bactericides, insecticides and miticides, and herbicides. Using available information on resistance and local crop and pest conditions NZCPR develops and publishes guidelines for resistance management, which are, where possible, consistent with international guidelines. Full pesticide resistance prevention and management strategies for New Zealand are freely available on the NZPPS website (www.nzpps.org) and information on resistance management is placed on product labels.

New Zealand has a relatively good historical record for preventing pesticide resistance and there are many instances where resistance problems that have developed overseas for particular pesticide groups have not occurred in New Zealand (Martin et al. 2005). This is attributable, at least in part, to a cautious and responsible approach over a long period of time by the agrichemical industry through the New Zealand Association for Animal Health and Crop Protection (AGCARM), various crop sector associations and agricultural research institutions, under the guidance of NZCPR. 


\section{IMPLEMENTATION OF RESISTANCE MANAGEMENT GUIDELINES}

Resistance management strategies are primarily implemented through pesticide product labels. NZCPR is currently developing mode of action (MOA) label codes to show which products share active ingredients with the same biochemical activity. This will allow pesticide users to understand which products should or should not be mixed or applied in succession and to determine which products are covered by the total number of applications for a given MOA group. This is being done in accordance with existing code systems used by the international fungicide, insecticide and herbicide resistance action committees (FRAC, IRAC and HRAC) and CropLife Australia. For insecticides and fungicides the international systems need few changes for New Zealand conditions. For herbicides, some of the resistance problems are unique to New Zealand and therefore the international codes will be adapted to suit our specific herbicide management requirements. The guidelines for resistance management that appear on product labels will in the future include the code(s) for the mode of action group(s), the maximum number of applications per season, when to apply alternative pesticides and whether to mix with another type of pesticide.

\section{RESISTANCE RESEARCH}

Pesticide resistance research has, historically, attracted little attention in New Zealand because of funding constraints for this area of science. In New Zealand, both government funding agencies and crop sector associations have tended to believe that resistance research is the responsibility of the agrichemical industry, to do with good product stewardship. This view has led to a paucity of local basic research and consequently a poor understanding of the true extent and nature of resistance in New Zealand. The agrichemical industry undertakes resistance monitoring and research in relation to product use recommendations, both in New Zealand and internationally. However, little information is available about resistance to older pesticides that are out of patent, but still widely used.

Pesticide resistance management must be seen as a collective responsibility involving all those who use pesticides and all those who produce products or services that rely on the use of pesticides. To manage pesticide resistance risks more effectively in New Zealand we require, in addition to overseas information, specific information about the resistance status of pests in New Zealand and a better understanding of the risk factors that cause resistance to develop.

\section{REFERENCES}

Elliott GS, Wearing CH, Suckling DM 1987. Formation of the New Zealand Committee on Pesticide Resistance. Proceedings of the $40^{\text {th }}$ New Zealand Weed \& Pest Control Conference: 84-89

Martin NA, Beresford RM, Harrington KC ed. 2005. Pesticide Resistance: Prevention and Management Strategies 2005. New Zealand Plant Protection Society Inc., Hastings, New Zealand. 166 p. 